\section{Reply to "Comparison of Maternity Care Training in Family Medicine Residencies 2013 and 2019: A CERA Program Directors Study"}

\section{TO THE EDITOR:}

We applaud Dr Fashner and colleagues for their analysis of the changes in perinatal care* training within family medicine residencies following the 2014 Accreditation Council for Graduate Medical Education (ACGME) requirements update. ${ }^{1}$ As leaders of the STFM Family Centered Maternity Care Collaborative, we share the authors' concerns that this decline in perinatal care training will detrimentally affect both our core identity as family physicians and the perinatal care workforce.

As family physicians, we pride ourselves on adjusting our skill set to meet the needs of our communities. Given the current perinatal health crisis ${ }^{2}$ and inequities in perinatal care, ${ }^{3}$ how can we remain faithful to this core value while simultaneously deemphasizing perinatal care training? Family physicians care for those most vulnerable to perinatal morbidity and mortality, including Black, Indigenous, and People of Color (BIPOC), trauma survivors, Medicaid beneficiaries, and rural residents. ${ }^{4,5}$ With our training in social justice, comprehensive reproductive care, and care of families, we can help communities meet the goals of reproductive justice. ${ }^{6}$ If we are to truly care for all families, we must make a firm, unequivocal commitment to perinatal training in family medicine residency.

The forces that prompted the 2014 ACGME change, including institutional barriers limiting procedural volume, have not gone away. Despite these constraints, some programs are still able to consistently train residents to competency in perinatal care. ${ }^{1}$ It is critical that our governing bodies, including the ACGME, support these programs by protecting their training against further institutional threats. To do this, we must have clear, rigorous national standards for competency, ${ }^{7}$ as well as transparency about the scope of training provided at each program. Many students are drawn to family medicine because of the opportunity to provide full-scope care, including perinatal care $^{8}$; we should not lose these future primary care providers by limiting our scope. We also must support family medicine faculty who teach and model perinatal care, particularly BIPOC faculty, given the lack of racial and ethnic diversity in the family medicine perinatal care workforce. ${ }^{9}$

Training residents to provide perinatal care is wasted effort if graduates are unable to practice to the full extent of their abilities. ${ }^{10}$ National family medicine organizations must advocate to reenvision health systems with a foundation of full-scope family physicians, especially in rural communities. For too long, advocacy for one specialty has meant competition with others; family medicine should be a leader in interdisciplinary collaboration to improve perinatal care. We must partner with community birth advocates, midwives, and obstetrician/gynecologists to ensure improved experiences for all birthing people and families.

As we strive to retain perinatal care in family medicine, we cannot forget the big picture. Our health care system perpetuates corporate profits, structural violence, and systemic racism at the expense of the people it purports to serve. Thus it should come as no surprise that providing excellent, comprehensive care to families, and training residents to do the same, often feels like a losing proposition. To truly meet the needs of our communities, including equitable and comprehensive reproductive care, we must continue to fight for health care revolution. ${ }^{11,12}$

doi: 10.22454/FamMed.2022.946530

Claire Thomson, MD, MPH

Swedish First Hill Family Medicine Residency

Jessica Taylor Goldstein, MD

University of New Mexico Family Medicine Residency

Christine Pecci, MD

University of California Family Medicine Residency

Fareedat Oluyadi, MD

University of North Carolina Family Medicine Residency

Sara Shields, MD

University of Massachusetts Family Medicine Residency

Narges Farahi, MD

University of North Carolina Family Medicine Residency

* Note: "perinatal care" is used in lieu of "maternity care" for purposes of gender inclusivity. 


\section{References}

1. Fashner J, Cavanagh C, Eden A. Comparison of maternity care training in family medicine residencies 2013 and 2019 . a CERA program directors study. Fam Med. 2021;53(5):331337. doi:10.22454/FamMed.2021.752892

2. Pregnancy Mortality Surveillance System. Centers for Disease Control and Prevention. Accessed June 4, 2021. https://www.cdc.gov/reproductivehealth/maternal-mortality/ pregnancy-mortality-surveillance-system.htm

3. Birth Equity for All Black Birthing People. National Birth Equity Collaborative. Accessed June 4, 2021. https:// birthequity.org/

4. Young RA. Maternity care services provided by family physicians in rural hospitals. J Am Board Fam Med. 2017;30(1):71-77. doi:10.3122/jabfm.2017.01.160072

5. Kozhimannil KB, Fontaine P. Care from family physicians reported by pregnant women in the United States. Ann Fam Med. 2013;11(4):350-354. doi:10.1370/afm.1510

6. Reproductive Justice. Sister Song Women of Color Reproductive Justice Collective. Accessed June 4, 2021. https://www. sistersong.net/reproductive-justice

7. Magee SR, Eidson-Ton WS, Leeman L, et al. Family medicine maternity care call to action: moving toward national standards for training and competency assessment. Fam Med. 2017;49(3):211-217.

8. Alavi M, Ho T, Stisher C, et al. Factors that influence student choice in family medicine: a national focus group. Fam Med. 2019;51(2):143-148. doi:10.22454/FamMed.2019.927833

9. Eden AR, Taylor MK, Morgan ZJ, Barreto T. Racial and ethnic diversity of family physicians delivering maternity care. J Racial Ethn Health Disparities. 2021; Epub ahead of print. doi:10.1007/s40615-021-01055-y

10. Barreto TW, Eden AR, Hansen ER, Peterson LE. Barriers faced by family medicine graduates interested in performing obstetric deliveries. J Am Board Fam Med. 2018;31(3):332333. doi:10.3122/jabfm.2018.03.170427

11. Chen FM. STFM for All. Fam Med. 2019;51(6):535-536 doi:10.22454/FamMed.2019.966678

12. Cullen, J. AAFP Letter for the Senate Finance Committee RFI on Maternal Health. April 3, 2020. Accessed June 4, 2021. https:/www.aafp.org/dam/AAFP/documents/advocacy/prevention/women/LT-SenateFinance-MaternalHealth-040320.pdf

\section{In Response to "Reenvisioning Family Medicine Residency Education"}

\section{TO THE EDITOR:}

The July-August 2021 Family Medicine special issue, "Reenvisioning Family Medicine Residency Education" focused on several important elements of the philosophy, content, and delivery of resident education." In addition to the elements presented by the authors, residents' careers and well-being are affected by their financial literacy education, or lack thereof.

Residents have a relatively poor state of financial health and literacy and have identified financial health as an important source of stress and burnout., ${ }^{2,3}$ This is particularly important for family medicine residents; a recent study demonstrated that the indebtedness of family medicine residents is increasing even faster than the average of all US allopathic graduates. ${ }^{4}$ Crucially, more than $90 \%$ of respondents want financial literacy education (eg, debt, insurance, purchasing a home). ${ }^{5}$

Notably, high debt burden may influence whether family medicine residents choose to enter academic medicine. ${ }^{6} \mathrm{~A}$ financial literacy program can provide residents with the confidence to manage their existing obligations and avoid further debt so that finances do not become a deterrent to pursuing an academic career. Adding required financial literacy education is in service of our goal to improve the well-being of our residents and potentially increase the number of academic family physicians.

This is a contributor to burnout that we can address through the existing infrastructure of the required Health Systems Management curriculum. Family medicine is uniquely positioned to integrate this into our curriculum standards. The specialty was the first to implement a practice management curriculum requirement where 100 hours (or 1 month) is required by the Accreditation Council for Graduate Medical Education for Family Medicine. ${ }^{7,8}$ Personal finance would only strengthen topics such as an understanding of contracts and utilizing resources to enhance physician well-being, both of which are included in the recommended Health Systems Management Guidelines by the American Academy of Family Physicians. ${ }^{9}$ Moreover, short curricular interventions in resident populations have been studied with positive results. There are multiple ways to incorporate this into the curriculum, including guest lectures, assigned reading, faculty/advisor discussions, and didactic sessions. ${ }^{10}$

The evidence is clear regarding financial literacy education: (1) the literature has identified an educational gap, (2) there is strong resident desire for this education that is congruent with our mission as family medicine educators, and (3) it is feasible. If the intention of the Health Systems Management Guidelines is to prepare our resident physicians for the real world, we must include personal finance in that discussion. 
doi: 10.22454/FamMed.2022.839637

\section{Stacy Bartlett, MD}

University of Pittsburgh School of Medicine -

Family Medicine

Pittsburgh, PA

1. Reenvisioning Family Medicine Residency Education. Fam Med. 2021;53(7)

2. Jennings JD, Quinn C, Ly JA, Rehman S. Orthopaedic surgery resident financial literacy: an assessment of knowledge in debt, investment, and retirement savings. Am Surg. 2019;85(4):353-358. doi:10.1177/000313481908500424

3. Kovar A, Carmichael H, Harms B, Nehler M, Tevis S. Over worked and under paid: how Resident finances impact perceived stress, career choices, and family life. J Surg Res. 2021;258:82-87. doi:10.1016/j.jss.2020.07.084

4. Phillips JP, Morgan ZJ, Bazemore AW, Peterson LE. Debt of family medicine residents continues to grow. $J$ Am Board Fam Med. 2021;34(3):663-664. doi:10.3122 jabfm.2021.03.200567

5. McKillip R, Ernst M, Ahn J, Tekian A, Shappell E. Toward a resident personal finance curriculum: quantifying resident financial circumstances, needs, and interests. Cureus. 2018;10(4):e2540. doi:10.7759/cureus.2540
6. Phillips JP, Peterson LE, Fang B, Kovar-Gough I, Phillips RL Jr. Debt and the emerging physician workforce: the relationship between educational debt and family medicine residents' practice and fellowship intentions. Acad Med. 2019;94(2):267-273. doi:10.1097/ACM.0000000000002468

7. ACGME Program Requirements for Graduate Medical Education in Family Medicine. Accreditation Council for Graduate Medical Education. July 2020. Accessed November 10, 2021. https://www.acgme.org/Portals/0/PFAssets/ ProgramRequirements/120_FamilyMedicine_2020.pdf

8. Kolva DE, Barzee KA, Morley CP. Practice management residency curricula: a systematic literature review. Fam Med. 2009;41(6):411-419.

9. Recommended Curriculum Guidelines for Family Medicine Residents Health Systems Management. American Academy of Family Physicians. Accessed November 10 2021. https://www.aafp.org/dam/AAFP/documents/medical_education_residency/program_directors/Reprint290C_ Health\%20Systems\%20Management.pdf

10. Walsh DW, Sullivan WM, Thomas M, Duckett A, Keith $\mathrm{B}$, Schreiner AD. A multicenter curricular intervention to address resident knowledge and perceptions of personal finance. South Med J. 2021;114(7):404-408. doi:10.14423/ SMJ.0000000000001272 